\title{
Expression pattern of $T$-helper 17 cell signaling pathway and mucosal inflammation in celiac disease
}

\author{
Anne Lahdenperä, Karin Fälth-Magnusson, Lotta Hogberg, \\ Johnny Ludvigsson and Outi Vaarala
}

\section{Linköping University Post Print}

\section{Tweet}

N.B.: When citing this work, cite the original article.

Original Publication:

Anne Lahdenperä, Karin Fälth-Magnusson, Lotta Hogberg, Johnny Ludvigsson and Outi Vaarala, Expression pattern of T-helper 17 cell signaling pathway and mucosal inflammation in celiac disease, 2014, Scandinavian Journal of Gastroenterology, (49), 2, 145-156.

http://dx.doi.org/10.3109/00365521.2013.863966

Copyright: Informa Healthcare http://informahealthcare.com/

Postprint available at: Linköping University Electronic Press http://urn.kb.se/resolve?urn=urn:nbn:se:liu:diva-104288 


\section{Expression pattern of Th17 signalling pathway and mucosal inflammation in celiac disease}

Anne I. Lahdenperä ${ }^{1}$, Karin Fälth-Magnusson ${ }^{1,2}$, Lotta Högberg ${ }^{3}$, Johnny Ludvigsson ${ }^{1,2}$, Outi Vaarala $^{4}$

${ }^{1}$ Division of Paediatrics, Department of Clinical and Experimental Medicine, Faculty of Health Sciences, Linköping University, Linköping, Sweden.

${ }^{2}$ Department of Pediatrics, County Council of Östergötland, Linköping, Sweden.

${ }^{3}$ Department of Pediatrics, Norrköping Hospital, County Council of Östergötland Norrköping, Sweden.

${ }^{4}$ Immune Response Unit, Department of Vaccination and Immune Protection, National Institute for Health and Welfare, Helsinki, Finland.

Correspondence to: $\quad$ Anne Lahdenperä

Clinical Experimental Research

Division of Paediatrics

Faculty of Health Sciences

Linköping University

S-581 85 Linköping

Sweden

Phone: +46-(0)10-103 3565

Fax: +46-(0)13-12 7465

e-mail: anne.lahdenpera@liu.se

The authors have no conflicts of interest to declare. 


\section{Abstract}

Objective: We aimed to investigate the mucosal activation of a broad range of genes associated with the Th17 signalling pathway in children at different stages of CD; including children with increased risk for $\mathrm{CD}$, children with untreated and gluten-free diet (GFD)-treated $\mathrm{CD}$.

Material \& methods: Small intestinal biopsies were taken from children with untreated and GFDtreated $\mathrm{CD}$, transglutaminase antibody (TGA) positive children with potential CD and reference children. Real-time PCR-arrays were used to study the gene expression pattern of Th17 related genes and qPCR was used to study the IL-17A expression.

Results: The mucosal expression of CD8A was elevated at all stages of CD. Children with untreated CD had diminished levels of IL-17RE, IL-23R, RORc, STAT6, CCL22, NFATC2, IL-18, CD4, CD247 and matrix metalloproteinase(MMP)9, but elevated levels of MMP3, IL-17, IFN- $\gamma$ and CD8A, compared to references. The majority of the aforementioned genes, being differentially expressed in untreated CD, displayed similar expression in GFD-treated children and references. Children with untreated and GFD-treated CD had elevated expression of IFN- $\gamma$, but reduced expression of CD247. Interestingly, children with potential CD displayed reduced FOXP3, IL-21 and IL-17A levels.

Conclusion: Mucosal up-regulation of Th17 immunity occurs at the late stage of disease and is down-regulated with dietary treatment indicating that IL-17 immunity is not a fundamental feature of CD as Th1 immunity, which is not fully down-regulated by GFD.

Key words: Arrays, celiac disease, children, FOXP3, gene expression, gluten free diet, IL-17, mucosa, Th17. 


\section{Introduction}

Celiac disease $(\mathrm{CD})$ is a common autoimmune disorder which develops in genetically susceptible individuals, positive for HLA-DQ2/DQ8, as a result of intolerance to dietary gluten. CD has often been considered as a classical malabsorption state characterized by severe mucosal villous atrophy with crypt hyperplasia together with immune cell infiltration and inflammation in the small intestinal mucosa. Nowadays, also mild inflammation with partial villous atrophy is becoming a more common phenotype of $\mathrm{CD}$ at presentation. Individuals with elevated $\mathrm{CD}$ associated transglutaminase autoantibodies without villous atrophy, who are considered to have increased risk of $\mathrm{CD}$ and so called potential $\mathrm{CD}$, are also a part of the broad spectrum of $\mathrm{CD}$. Approximately one third of the subjects with potential CD developed villous atrophy and acute CD within a few years if they continued on a gluten containing diet [1]. So far the only available treatment of CD is a lifelong strict gluten-free diet (GFD), which causes clinical improvement and normalization of the villous atrophy together with improvement of the intestinal inflammation.

It is known that $\mathrm{CD}$ is characterized by mucosal up-regulation of the interferon (IFN)- $\gamma$ pathway [24]. Gluten reactive T-cells have been shown to secrete IFN- $\gamma$, emphasizing the role of T-helper (Th)1 associated immune responses in the pathogenesis [5]. We recently reported that children with untreated CD displayed mucosal up-regulation of the IFN- $\gamma$ pathway, which remained elevated even one year after GFD treatment. This suggests that activation of the Th1 response seems to be more fundamentally associated with $\mathrm{CD}$, being present already in individuals with potential $\mathrm{CD}$ and also remaining in GFD-treated CD patients with normal villous structure [6].

Recently elevated interleukin (IL)-17 responses were reported after exposure to wheat gliadin in acute $\mathrm{CD}$ but not in potential CD indicating association of up-regulated IL-17 pathway with villous atrophy [7-9]. However, T-cell clones reactive with deamidated gliadin peptide did not show IL-17 
secretion [5] which suggests that activation of IL-17 may not be induced directly by dietary gluten, but rather develops at later stage of mucosal inflammation. IL-17 has been speculated to act as a counter-regulatory molecule limiting the intestinal inflammation (induced by Th1 cells) [8]. We have reported that IL-17 induced anti-apoptotic bcl-2 responses in an intestinal epithelial cell line [9]. Another regulatory factor, FOXP3, has been reported to be up-regulated also in acute CD. In summary, the complex network of mucosal immune activation in CD is poorly understood and it seems that changing pattern of Th1/Th17/Treg activation is seen at different stages of CD.

To understand the role of IL-17 immunity in CD, we analysed the intestinal expression profile of Th17 related genes in reference children, children with transglutaminase antibody (TGA) positivity (potential CD), and in children with untreated CD and GFD-treated CD. 


\section{Methods}

\section{Study subjects}

Small intestinal biopsy samples were obtained from 33 children (mean age: 6.9 years, range 1-18 years, 21 girls and 12 boys) who underwent small intestinal biopsy sampling at the Paediatric Clinic, University Hospital Linköping or at the Paediatric Clinic in Norrköping or Motala for suspicion of or confirmation of CD (Table 1). The study population comprises four groups: nine children with untreated CD displaying a morphological picture of $\mathrm{CD}$ (untreated CD); eight CD children who have followed a strict exclusion diet for one year with a normalized mucosa (GFD treated $\mathrm{CD}$ ); eight children with potential $\mathrm{CD}$, i.e. TGA-positive children having a normal mucosa and following gluten contain diet (potential CD); and eight TGA negative children displaying a morphologically normal mucosa (references).

\section{RNA preparation}

Cryopreserved biopsies were used for RNA isolation, according to standardized methodology at our laboraory as described previously [6]. Total RNA was isolated from frozen biopsies, DNase treated and quality checked using Agilent 2100 Bioanalyzer (Agilent Technologies) according to the manufacturers' guidelines, as described before [6].

\section{Th17 signalling pathway PCR array}

For the real-time PCR-array analyses, $1.4 \mu \mathrm{g}$ of total RNA was reversly transcribed into cDNA (15 min at $42^{\circ} \mathrm{C}$ and 5 min at $95^{\circ} \mathrm{C}$ ), mixed into a PCR-cocktail (together with DNA polymerase, SYBR ${ }^{\circledR}$ Green dye, ROX reference dye and double-distilled $\mathrm{H}_{2} \mathrm{O}$ ) and loaded on the Human Th17 for Autoimmunity \& Inflammation RT² ProfilerTM PCR Array (PAHS-073, SABiosciences, Frederick, Maryland, USA). Subsequently, PCR amplification was performed (10 $\mathrm{min}$ at $95^{\circ} \mathrm{C}, 40$ 
cycles of $15 \mathrm{~s}$ at $95^{\circ} \mathrm{C}, 1 \mathrm{~min}$ at $60^{\circ} \mathrm{C}$ ), according to the manufacturer's guidelines, as described earlier [6].

Only genes with threshold cycle $(\mathrm{Ct})$-values $<35$ were considered to be detectable, according to the manufacturer's guidelines. The Ct-values of the genes were normalized with the average Ct-value of all five housekeeping genes (HKG) on the array: Beta-2-microglobulin (B2M), Hypoxanthine phosphoribosyltransferase 1 (HPRT1), Ribosomal protein L13a (RPL13A), Glyceraldehyde-3phosphate dehydrogenase (GAPDH) and $\beta$-actin (ACTB). The $\Delta \mathrm{Ct}$ and the median fold change $\left(2^{-}\right.$ MEDIAN $\Delta \Delta C \mathrm{Ct}$ ) were calculated for the genes on the array.

\section{Quantitative RT-PCR}

The mucosal expression of IL-17 was undetectable with the PCR-arrays and was therefore analysed with conventional quantitative PCR (qPCR), which is a more sensitive method for IL-17 detection. For qPCR (qPCR) of IL-17A, total RNA was reversely transcribed into cDNA using TaqMan Reverse Transcription reagents (Applied Biosystems, Foster City, CA). qPCR of IL-17A (cat. no. Hs00174383_m1) was then carried out using TaqMan Gene Expression Assay (Applied Biosystems), as described earlier [9]. 18s rRNA was used as endogenous control (Hs99999901_s1) and an exogenous cDNA pool calibrator as an interassay standard to which normalized samples were compared. The relative expression level of IL-17A was quantified using the comparative $\Delta \Delta C \mathrm{t}$ method, where $2^{-\Delta \Delta C \mathrm{t}}$ represents the relative amount of the gene of interest in the sample, according to the manufacturer's guidelines, as described earlier [9]. For presentations the relative amounts $\left(2^{-\Delta \Delta C t}\right)$ of IL-17 was multiplied by a factor 1000 and expressed as relative units. To enable statistical analyses if the $C_{\mathrm{t}}$ value not reached a quantitative level, an artificial value corresponding to half of the lowest quantitative value in relative units was given to the sample. 


\section{Statistical analysis}

The data analysis was performed with SPAW Statistics 17.0 for Windows (SPSS Inc., Chigaco, IL, USA) and GraphPad prism software (San Diego, CA). Mann-Whitney U test was used for comparisons between the groups and p-values $<0.05$ were considered as statistically significant.

For the PCR-arrays a cut off criterion for the gene expression fold change $\left(2^{- \text {MEDIAN } \triangle \Delta C t}\right)$ between the samples was used. A fold change of 1.4 was considered to be an enhancement, whereas a fold change of -1.4 was considered to be a reduction of the studied genes. The difference in the gene expression between the groups was considered significant if it fulfilled the following two criteria: a fold change of $( \pm 1.4)$ together with a p-value of $<0.05$ between the groups, as described before [6]. The statistical analyses were not corrected for multiple comparisons.

The expression profiles of genes passing the double cut-off criterion were visualised with Self Organizing Map (SOM)-clusters formed by GeneCluster 2.0 (Whitehead Institute, Center for Genome Research, Massachusetts Institute of Technology, Cambridge, MA), using Tamayo’s algorithm [10]. The expression data was pre-processed by normalization (mean: 0, variance: 1) before it was clustered according to Tamayo et al [10] as described before [6].

In order to disclose multivariate responses Principal Component Analysis (PCA) of the HKGnormalised Real time-PCR-array data was employed, using GeneEx (MultiD Analyses/TATAA Biocenter, Gothenburg, Sweden). The data was pre-processed by calculating the relative expression of the genes, log2-transformation and mean-centering. Genes passing the double cut-off criteria; the fold change cut-off $( \pm 1.4)$ together with a significant difference in gene expression between the study groups (Mann-Whitney U test $(\mathrm{p}<0.05)$ between children with untreated-CD and/or GFDtreated-CD and/or children without $\mathrm{CD}$ (references + potential $\mathrm{CD}$ ) were visualised with PCA. 


\section{Ethical Considerations}

The study was approved by the Regional Ethics Committee for Human Research at the University Hospital of Linköping, Sweden, and written informed consent was obtained from parents and the children who were old enough to agree to participation. 


\section{Results}

Detectable PCR-array products ( $<35$ cycles) were obtained from the majority $(n=72)$ of the 84 genes associated with the Th17 signalling pathway (Supplementary Table 1). The expression of 61 genes in total differed (with a fold change value higher than \pm 1.4 ) among the groups of children studied (Figure 1). The expression level; $\Delta$-Ct-value, of 23 genes was statistically different between the groups (Supplementary Table 2). The Ct-values of IL-17A in the samples were all below 35 cycles, which is the cut off level for detection in the PCR arrays. The expression of IL-17A was analyzed with conventional qPCR, due to its higher sensitivity [9]. The IL-17A levels of the samples analyzed with qPCR displayed moderate mRNA expression (median Ct-value: 31.6; range 28.1-40 cycles).

\section{Cluster analysis}

Unsupervised cluster analysis (SOM-clustering) of the 23 genes passing the double cut-off criterion displayed 4 distinct clusters; C0-C3, including 5, 3, 5 and 10 genes respectively (Figure 2).

\section{Mucosal gene expression in potential CD}

Children with potential CD had elevated CD8A gene expression level, but reduced IL-21, FOXP3, CSF2, TRAF6, MMP9 and CLEC7A expression when compared to the references (Figure 2-3, Supplementary Table 2). Children with potential CD had reduced expression of FOXP3 and CLEC7A compared to untreated CD and GFD treated CD, respectively (Figure 2-3, Supplementary Table 2). The expression of CD4, IL-17RE, RORc, NFATC2 and IL-18 was higher in potential CD in comparison to untreated CD (Figure 2, 4, Supplementary Table 2). Interestingly, the qPCR analyses of IL-17 showed that children with potential CD expressed lower levels of IL-17A than the reference children, but also compared to children with untreated and GFD-treated CD (Figure 3). 


\section{Mucosal gene expression in untreated and GFD-treated CD}

Children with untreated CD had elevated expression of IFN- $\gamma$, IL-17A, MMP3, CD3D, CD3G and CD8A, but reduced expression of IL-17RE, IL-23R, RORc, NFATC2, CD4, CD247, IL-18, CCL22, STAT6, MMP9 and TRAF6 when compared to the reference children (Figure 2-5, Supplementary Table 2). In GFD-treated CD, the expression of IL-17A, MMP3, IL-17RE, IL-23R, RORc, NFATC2, CD4, IL-18, and STAT6 was similar as the references and therefore seemed to be normalised by GFD-treatment (Figure 2, 4-5, Supplementary Table 2). Similarly as children with untreated CD, the GFD-treated children displayed enhanced IFN- $\gamma$, CD3D, CD3G and CD8A expression, but diminished CD247 expression when compared to the references. Furthermore, the GFD-treated children expressed lower levels of IL-21 than the reference group (Figure 2-3, Supplementary Table 2).

The expression of TIRAP, IL-6R and IL-7R was lower in untreated CD in comparison to GFDtreated CD (Figure 2, Supplementary Table 2). qPCR analyses showed that IL-17A transcripts were elevated in children with untreated CD as compared to GFD-treated CD children (Figure 3).

\section{Principal component analysis (PCA)}

Principal component analysis (PCA) of the 23 differentially expressed genes; CCL22, CD247, CD3D, CD3G, CD4, CD8A, CLEC7A, CSF2, FOXP3, IFN- $\gamma$, IL-17RE, IL-18, IL-21, IL-23R, IL6R, IL-7R, MMP3, MMP9, NFATC2, RORc, STAT6, TIRAP and TRAF6, revealed separation of the groups; children with untreated $\mathrm{CD}$, GFD-treated $\mathrm{CD}$, potential $\mathrm{CD}$ and reference children without CD (Figure 6). 


\section{Discussion}

During recent years the role of IL-17 immunity in CD has received a lot of interest due to the key function of Th17 immunity in mucosal defence. Here, we used real-time PCR arrays, an applicable tool for gene expression studies [11] [6] to analyse the mucosal immune activation stage of a broad range of Th17 related genes in small intestinal biopsies from children at different stages of CD i.e. untreated, potential and GFD-treated CD.

We found that children with untreated CD and villous atrophy expressed elevated levels of IFN- $\gamma$, IL-17A, MMP3 and CD8A but diminished levels of IL-17RE, RORc, NFATC2, CCL22, CD4, CD247, IL-18 and STAT6 as compared to the reference children. The elevated expression of CD8A was observed in all stages of CD; i.e. in potential, untreated and GFD-treated CD. This indicates that activation of the cytotoxic T-cells $(\mathrm{Tc})$ is a basic feature in $\mathrm{CD}$ related mucosal inflammation and not only triggered by gliadin because it is still seen after one year on GFD. As expected, high levels of mucosal IFN- $\gamma$ expression were seen in children with GFD-treated CD when compared to the references indicating that the dysregulated IFN- $\gamma$ response is not normalized by a strict GFDtreatment for one year. Thus, elevated mucosal IFN- $\gamma$ and CD8A in patients on GFD suggests that Th1 activation is the underlying mucosal immune aberrancy in CD and not totally down-regulated by dietary treatment. These results also suggest that in the etio-pathogenesis of CD an unknown factor which not is gliadin is playing a role. The dysregulated Th2 response in untreated CD, characterised by reduced CCL22, IL-18 and STAT6 levels, is likely a reflection of the increased Th1 response since these changes were normalized by the GFD-treatment. This is in agreement with previous studies $[6,12]$. 
Our results also show that the mucosal IL-17A response was elevated at the late stage of CD when villous atrophy has developed. Mucosal IL-17A displayed elevated expression in children with untreated $\mathrm{CD}$ when compared to GFD treated children and also when compared to children with potential $\mathrm{CD}$. This is in agreement with previous studies $[8,9,12,13]$. In contrast to the elevated IL-17A level in untreated CD, the expression of RORc, IL-17RE and IL-23R was diminished. RORc is a transcription factor for IL-17 activation, IL-23R is expressed on Th17 cells and IL-23 is important for the maintenance of IL-17 secretion. It seems that there are simultaneous attempts to regulate the increased mucosal IL-17 immunity in CD. Alternatively, IL-17 transcripts are not upregulated in the "classical" Th17 cell, but in T-cells which show plasticity. It was recently reported that gliadin-specific mucosal Th17 cells of patients with CD are different from Th17 cells of healthy individuals [14]. Th17 cells in CD show plasticity; they secrete pro-inflammatory cytokines such as IL-17, IFN- $\gamma$, IL-21, but also mucosa-protective IL-22 and regulatory TGF- $\beta$ [14]. The role of IL-17 expressing cells may thus be dualistic in CD mucosa. It has been suggested that IL-17 upregulation in mucosa is actually related to the mechanisms of protection [8]. In a previous study we showed that IL-17 induced anti-apoptotic rather than apoptotic responses in an epithelial cell line [9]. IL-17 in mucosal anti-microbial defence has been shown to contribute to the gut barrier function and up-regulation of IL-17 diminishes the dissemination of pathogens from the intestinal lumen [15]. Furthermore, the small intestinum seems to be responsible for the control of the response by eliminating Th17 cells and by induction of a phenotype change in Th17 cells, which acquire suppressive phenotype characteristics and participate in the regulation of immune responses in small intestine [16].

On the other hand commensal bacteria can induce mucosal IL-17 response [17-20], and it is possible that changes in microbiota could be responsible for the up-regulation of IL-17 when villous atrophy develops. Alterations of intestinal microbiota are seen in active CD [21-25], but the 
importance of microbes as triggers of mucosal damage has not been proven. The innate immunity associated markers TIRAP and TRAF6, which are involved in TLR signalling pathways, were also diminished in children with untreated CD compared to the GFD-treated CD children and the references. The expression of both markers was similar in the references as in children following a strict GFD for one year. These findings might reflect the alterations in the microbiota in untreated $\mathrm{CD}$, which previously has been reported in CD [25-29].

Interestingly, IL-17A gene expression together with FOXP3 and IL-21 expression were markedly reduced in children with potential CD when compared to all other groups of children. Diminished IL-21 levels have earlier been reported in potential CD as compared to patients with untreated CD and controls [30]. Accordingly, the activation of mucosal Th1 immunity alone, as seen in potential $\mathrm{CD}$ and treated $\mathrm{CD}$, may not lead to the villous atrophy, but additional immunological changes are needed. In addition to IL-17, the expression of MMPs was up-regulated at the time of villous atrophy.

Our results show that MMP3 was enhanced in untreated CD with villous atrophy when compared to the references, which is in agreement with previous studies reporting elevated MMP3 expression, both at mRNA and protein level, in children with untreated CD [31, 32]. We show here that MMP3 levels in the GFD-treated children did not differ from those in the reference group. GFD seems to induce a normalization of the MMP3 expression concurrently with the normalization of the intestinal mucosa. The simultaneous up-regulation of MMP3 and IL-17 seen in our study is of interest, since it was reported that IL-17 may induce secretion of MMP3 in vitro [33]. Also IFN- $\gamma$ has been shown to up-regulate MMPs [34]. MMPs are known to be involved in tissue remodelling, but may also cause degradation of the extracellular matrix and basement membranes and thereby promote influx of immune cells to the intestinal epithelium and contribute to the intestinal 
inflammation. It is likely that MMP3 are involved in the pathogenesis of CD of epithelial destruction at the time of villous atrophy in $\mathrm{CD}[35]$.

The reduced expression of CD247, CD4, and NFATC2 which was seen in CD children with villous atrophy may indicate that the T-cell activation and signalling is disturbed in untreated CD. CD247 is an amplification module in the TCR/CD3 signalling cascade, but also a master regulator and sensor of innate and adaptive immune responses. A defective expression/function of CD247 was suggested to be associated with pro-inflammatory conditions, autoimmune diseases and refractory CD [36-40]. Cells expressing low levels of CD247 produce IFN- $\gamma$, but they do also possess enhanced migratory capacity and the ability to enrich in inflamed tissues [37]. It is however unknown if the down-regulation of CD247, which often occur concurrently with Th1 responses, is induced by or a consequence of the inflammatory response. Down-regulation of CD247 most likely represents a beneficial mechanism attenuating hyper-activated immune responses in acute inflammatory conditions [41]. NFATC2 is a multi-faceted activation marker, important for cytokine production by peripheral T-cells, which also has been suggested to regulate mucosal T-cell activity and to be important in innate mucosal immune responses [42]. Treatment with a GFD seems to normalise the defective T-cell activation and signalling, since the expression of the aforementioned genes were similar in GFD-treated CD and references. Thus, the diminished expression of these genes involved in T-cell signalling and activation most likely represents a normal mechanism by which the immune system regains homeostasis/balance during inflammatory conditions.

Multivariate data analysis techniques such as PCA and cluster analysis are nowadays more common used for analysis and visualization of expression data. Here, four distinct clusters were formed when SOM-clustering was used to display the expression pattern of the 23 differentially expressed genes in children at different stages of CD. In our study, the PCA separated the groups of children with 
untreated CD from children with GFD-treated CD, potential CD and reference children without CD. The 23 genes included in the PCA comprise genes directly involved in IL-17 pathway, such as IL17 RE, IL-23R, IL-21, RORc and IL-6R, and also other genes related to T-cell activation and regulation, such as IFN- $\gamma$, CD247, CD3D, CD3G, CD4, CD8A, NFATC2, STAT6, FOXP3 and IL7R, but also genes involved in innate immunity, such as CLEC7A, CCL22, CSF2, IL-18, TIRAP, TRAF6 and MMP3. It should be noted that we did not corrected the statistical analyses for multiple comparisons, and thus the results should be interpreted with caution.

In summary, we show that the primary immune-pathogenesis of $\mathrm{CD}$ is characterized by the mucosal activation of IFN- $\gamma$ and CD8, which is present in potential CD and also in treated CD despite of the mucosal healing after elimination of dietary gluten. This may indicate that the fundamental cause of gliadin intolerance is a trigger of this kind of cytotoxic T-cell immunity often induced by intracellular pathogens. Although the role of IL-17 and MMPs is not fully understood in the pathogenesis of $\mathrm{CD}$, their up-regulation at the time of villous atrophy suggests that IL-17 and MMPs could be explored as useful biomarkers of active CD in the follow-up of individuals with potential CD. 


\section{Acknowledgements}

We thank all children \& adolescents that participated in the study. We thank Lars Stenhammar, Pia Laurin, Louise Forslund and Maria Nordwall at the Paediatric Clinics in Linköping, Norrköping and Motala are acknowledged for the clinical support. Harri Salo is acknowledged for the qPCR analyses. The research nurses at the Division of Paedatrics in Linköping, Norrköping and Motala and the laboratory technicians Gosia Konefal and Ingela Johansson are also thanked for the help with the sample collection. Rosaura Casas is acknowledged for her valuable input during the preparation of the manuscript.

This work was generously supported by the County Council of Östergötland, and the Swedish Child Diabetes Foundation (Barndiabetesfonden), the Swedish Research Council.

\section{Disclosure}

The authors have no conflict of interest to declare. 


\section{References}

1. Tosco A, Salvati VM, Auricchio R, Maglio M, Borrelli M, Coruzzo A et al. Natural history of potential celiac disease in children. Clin Gastroenterol Hepatol 2011; 9:320-5; quiz e36.

2. Kontakou M, Przemioslo RT, Sturgess RP, Limb GA, Ellis HJ, Day P et al Cytokine mRNA expression in the mucosa of treated coeliac patients after wheat peptide challenge. Gut 1995; 37:52-7.

3. Kontakou M, Sturgess RP, Przemioslo RT, Limb GA, Nelufer JM, Ciclitira PJ. Detection of interferon gamma mRNA in the mucosa of patients with coeliac disease by in situ hybridisation. Gut 1994; 35:1037-41.

4. Nilsen EM, Jahnsen FL, Lundin KE, Johansen FE, Fausa O, Sollid LM et al Gluten induces an intestinal cytokine response strongly dominated by interferon gamma in patients with celiac disease. Gastroenterology 1998; 115:551-63.

5. Bodd M, Raki M, Tollefsen S, Fallang LE, Bergseng E, Lundin KE et al. HLA-DQ2restricted gluten-reactive T cells produce IL-21 but not IL-17 or IL-22. Mucosal Immunol 2010; 3:594-601.

6. Lahdenpera A, Ludvigsson J, Falth-Magnusson K, Hogberg L, Vaarala O. The effect of gluten-free diet on Th1-Th2-Th3-associated intestinal immune responses in celiac disease. Scand J Gastroenterol 2011; 46:538-49.

7. Castellanos-Rubio A, Santin I, Irastorza I, Castano L, Carlos Vitoria J, Ramon Bilbao J. TH17 (and TH1) signatures of intestinal biopsies of CD patients in response to gliadin. Autoimmunity 2009; 42:69-73.

8. Monteleone I, Sarra M, Del Vecchio Blanco G, Paoluzi OA, Franze E, Fina D et al. Characterization of IL-17A-producing cells in celiac disease mucosa. J Immunol 2010; 184:2211-8.

9. Lahdenpera AI, Hölttä V, Ruohtula T, Salo HM, Orivuori L, Westerholm-Ormio M et al. Up-regulation of small intestinal IL-17 immunity in untreated celiac disease but not in potential celiac disease or in type 1 diabetes. Clin Exp Immunol: 2012; 167:226-34.

10. Tamayo P, Slonim D, Mesirov J, Zhu Q, Kitareewan S, Dmitrovsky E et al. Interpreting patterns of gene expression with self-organizing maps: methods and application to hematopoietic differentiation. Proc Natl Acad Sci U S A 1999; 96:2907-12.

11. Arikawa E, Sun Y, Wang J, Zhou Q, Ning B, Dial SL et al. Cross-platform comparison of SYBR Green real-time PCR with TaqMan PCR, microarrays and other gene expression measurement technologies evaluated in the MicroArray Quality Control (MAQC) study. BMC Genomics 2008; 9:328.

12. Bragde H, Jansson U, Jarlsfelt I, Soderman J. Gene expression profiling of duodenal biopsies discriminates celiac disease mucosa from normal mucosa. Pediatr Res 2011; 69:530-7.

13. Sapone A, Lammers KM, Mazzarella G, Mikhailenko I, Carteni M, Casolaro V et al. Differential mucosal IL-17 expression in two gliadin-induced disorders: gluten sensitivity and the autoimmune enteropathy celiac disease. Int Arch Allergy Immunol 2010; 152:75-80.

14. Fernandez S, Molina IJ, Romero P, Gonzalez R, Pena J, Sanchez F et al. Characterization of gliadin-specific Th17 cells from the mucosa of celiac disease patients. Am J Gastroenterol 2011; 106:528-38.

15. Blaschitz C, Raffatellu M. Th17 cytokines and the gut mucosal barrier. J Clin Immunol 2010; 30:196-203.

16. Esplugues E, Huber S, Gagliani N, Hauser AE, Town T, Wan YY et al. Control of TH17 cells occurs in the small intestine. Nature 2011; 475:514-8. 
17. Ivanov, II, Atarashi K, Manel N, Brodie EL, Shima T, Karaoz U, Wei D, Goldfarb KC, Santee CA, Lynch SV, Tanoue T, Imaoka A, Itoh K, Takeda K, Umesaki Y, Honda K, Littman DR. Induction of intestinal Th17 cells by segmented filamentous bacteria. Cell 2009; 139:485-98.

18. Ivanov II, Frutos Rde L, Manel N, Yoshinaga K, Rifkin DB, Sartor RB et al. Specific microbiota direct the differentiation of IL-17-producing T-helper cells in the mucosa of the small intestine. Cell Host Microbe 2008; 4:337-49.

19. Niess JH, Leithauser F, Adler G, Reimann J. Commensal gut flora drives the expansion of proinflammatory $\mathrm{CD} 4 \mathrm{~T}$ cells in the colonic lamina propria under normal and inflammatory conditions. J Immunol 2008; 180:559-68.

20. Lochner M, Berard M, Sawa S, Hauer S, Gaboriau-Routhiau V, Fernandez TD et al. Restricted microbiota and absence of cognate TCR antigen leads to an unbalanced generation of Th17 cells. J Immunol 2011; 186:1531-7.

21. Collado MC, Donat E, Ribes-Koninckx C, Calabuig M, Sanz Y. Imbalances in faecal and duodenal Bifidobacterium species composition in active and non-active coeliac disease. BMC Microbiol 2008; 8:232.

22. Collado MC, Donat E, Ribes-Koninckx C, Calabuig M, Sanz Y. Specific duodenal and faecal bacterial groups associated with paediatric coeliac disease. J Clin Pathol 2009; 62:264-9.

23. Forsberg G, Fahlgren A, Horstedt P, Hammarstrom S, Hernell O, Hammarstrom ML. Presence of bacteria and innate immunity of intestinal epithelium in childhood celiac disease. Am J Gastroenterol 2004; 99:894-904.

24. Nadal I, Donat E, Ribes-Koninckx C, Calabuig M, Sanz Y. Imbalance in the composition of the duodenal microbiota of children with coeliac disease. J Med Microbiol 2007; 56:166974.

25. Nistal E, Caminero A, Herran AR, Arias L, Vivas S, de Morales JM et al. Differences of small intestinal bacteria populations in adults and children with/without celiac disease: Effect of age, gluten diet, and disease. Inflamm Bowel Dis 2011; 18:649-56.

26. Ou G, Hedberg M, Horstedt P, Baranov V, Forsberg G, Drobni M et al. Proximal small intestinal microbiota and identification of rod-shaped bacteria associated with childhood celiac disease. Am J Gastroenterol 2009; 104:3058-67.

27. Tjellstrom B, Stenhammar L, Hogberg L, Falth-Magnusson K, Magnusson KE, Midtvedt T et al. Gut microflora associated characteristics in children with celiac disease. Am J Gastroenterol 2005; 100:2784-8.

28. Collado MC, Calabuig M, Sanz Y. Differences between the fecal microbiota of coeliac infants and healthy controls. Curr Issues Intest Microbiol 2007; 8:9-14.

29. De Palma G, Nadal I, Medina M, Donat E, Ribes-Koninckx C, Calabuig M et al. Intestinal dysbiosis and reduced immunoglobulin-coated bacteria associated with coeliac disease in children. BMC Microbiol 2010; 10:63.

30. Sperandeo MP, Tosco A, Izzo V, Tucci F, Troncone R, Auricchio R et al. Potential celiac patients: a model of celiac disease pathogenesis. PLoS One 2011; 6:e21281.

31. Daum S, Bauer U, Foss HD, Schuppan D, Stein H, Riecken EO et al. Increased expression of mRNA for matrix metalloproteinases-1 and -3 and tissue inhibitor of metalloproteinases1 in intestinal biopsy specimens from patients with coeliac disease. Gut 1999; 44:17-25.

32. Mohamed BM, Feighery C, Kelly J, Coates C, O'Shea U, Barnes L et al. Increased protein expression of matrix metalloproteinases $-1,-3$, and -9 and TIMP-1 in patients with glutensensitive enteropathy. Dig Dis Sci 2006; 51:1862-8.

33. Bamba S, Andoh A, Yasui H, Araki Y, Bamba T, Fujiyama Y. Matrix metalloproteinase-3 secretion from human colonic subepithelial myofibroblasts: role of interleukin-17. J Gastroenterol 2003; 38:548-54. 
34. Ciccocioppo R, Di Sabatino A, Bauer M, Della Riccia DN, Bizzini F, Biagi F et al. Matrix metalloproteinase pattern in celiac duodenal mucosa. Lab Invest 2005; 85:397-407.

35. Diosdado B, van Oort E, Wijmenga C. "Coelionomics": towards understanding the molecular pathology of coeliac disease. Clin Chem Lab Med 2005; 43:685-95.

36. Lundholm M, Mayans S, Motta V, Lofgren-Burstrom A, Danska J, Holmberg D. Variation in the $\mathrm{Cd} 3$ zeta $(\mathrm{Cd} 247)$ gene correlates with altered $\mathrm{T}$ cell activation and is associated with autoimmune diabetes. J Immunol 2010; 184:5537-44.

37. Zhang W, Luo FJ, Zhou JJ. Research progress on Th17 cells. Zhejiang Da Xue Xue Bao Yi Xue Ban 2007; 36:620-5.

38. Gorman CL, Russell AI, Zhang Z, Cunninghame Graham D, Cope AP, Vyse TJ. Polymorphisms in the CD3Z gene influence TCRzeta expression in systemic lupus erythematosus patients and healthy controls. J Immunol 2008; 180:1060-70.

39. Berg L, Ronnelid J, Klareskog L, Bucht A. Down-regulation of the T cell receptor CD3 zeta chain in rheumatoid arthritis (RA) and its influence on T cell responsiveness. Clin Exp Immunol 2000; 120:174-82.

40. Tjon JM, Verbeek WH, Kooy-Winkelaar YM, Nguyen BH, van der Slik AR, Thompson A et al. Defective synthesis or association of T-cell receptor chains underlies loss of surface Tcell receptor-CD3 expression in enteropathy-associated T-cell lymphoma. Blood 2008; 112:5103-10.

41. Baniyash M. TCR zeta-chain downregulation: curtailing an excessive inflammatory immune response. Nat Rev Immunol 2004; 4:675-87.

42. Weigmann B, Lehr HA, Yancopoulos G, Valenzuela D, Murphy A, Stevens S et al. The transcription factor NFATc2 controls IL-6-dependent T cell activation in experimental colitis. J Exp Med 2008; 205:2099-110. 
Table 1. Detailed information about the study population.

\begin{tabular}{|c|c|c|c|c|}
\hline CD-status & Age/Gender & TGA & $\begin{array}{l}\text { Marsh } \\
\text { grade }\end{array}$ & Comment \\
\hline Ref (TGA-) & $\mathrm{M} / 1.5$ & $\operatorname{Neg}(<4)$ & Marsh 0 & - \\
\hline Ref (TGA-) & $F / 1$ & $\operatorname{Neg}(<4)$ & Marsh 0 & IgA deficiency \\
\hline Ref (TGA-) & $\mathrm{F} / 2$ & $\operatorname{Neg}(<4)$ & Marsh 0 & (Mb Down) \\
\hline Ref (TGA-) & $M / 1$ & $\operatorname{Neg}(<4)$ & Marsh 0 & - \\
\hline Ref (TGA-) & $\mathrm{F} / 1.5$ & $\operatorname{Neg}(<4)$ & Marsh 0 & - \\
\hline Ref (TGA-) & $\mathrm{M} / 1$ & $\operatorname{Neg}(<4)$ & Marsh 0 & - \\
\hline Ref (TGA-) & $F / 10$ & $\operatorname{Neg}(<4)$ & Marsh 0 & Heredity \\
\hline Ref (TGA-) & $F / 1$ & $\operatorname{Neg}(<4)$ & Marsh 1 & Heredity \\
\hline Pot CD (TGA+) & $\mathrm{F} / 11$ & 9 & Marsh 0 & Pot-CD, Heredity \\
\hline Pot CD (TGA+) & $F / 10.5$ & 27 & Marsh 0 & Pot-CD \\
\hline Pot CD (TGA+) & $F / 9.5$ & 6 & Marsh 0 & Pot-CD, Heredity \\
\hline Pot CD (TGA+) & $\mathrm{M} / 3$ & 10 & Marsh 0 & Pot-CD \\
\hline Pot CD (TGA+) & $F / 11$ & 18 & Marsh 0 & Pot-CD \\
\hline Pot CD (TGA+) & $\mathrm{M} / 10$ & 6 & Marsh 0 & Pot-CD \\
\hline Pot CD (TGA+) & F/9.5 & 9 & Marsh 0 & $\begin{array}{l}\text { Pot-CD, New biopsy } \\
1 \text { year later: CD. }\end{array}$ \\
\hline Pot CD (TGA+) & $M / 8$ & 6 & Marsh 2 & $\begin{array}{c}\text { Pot-CD, New } \\
\text { Biopsy } 1 \text { year later: } \\
\text { CD. }\end{array}$ \\
\hline CD & $\mathrm{M} / 13$ & 10 & Marsh 1 & Heredity \\
\hline CD & $F / 18$ & 6 & Marsh 2 & - \\
\hline CD & $F / 5.5$ & $>100$ & Marsh $3 b$ & - \\
\hline CD & $\mathrm{M} / 9.5$ & 97 & Marsh 3b & - \\
\hline CD & $M / 13$ & 56 & Marsh 3b & - \\
\hline$C D$ & $F / 2$ & $\operatorname{Neg}(<4)$ & Marsh $3 b$ & - \\
\hline CD & $F / 2.5$ & $>100$ & Marsh 3b & - \\
\hline CD & $\mathrm{F} / 4$ & $>100$ & Marsh 3b & - \\
\hline$C D^{*}$ & $F / 2$ & 100 & Marsh 3c & - \\
\hline GFD-CD & $F / 17.5$ & NA & Marsh 0 & - \\
\hline GFD-CD & $F / 2.5$ & $\operatorname{Neg}(<4)$ & Marsh 0 & - \\
\hline GFD-CD & $F / 12.5$ & NA & Marsh 0 & - \\
\hline GFD-CD & $\mathrm{M} / 14$ & 4 & Marsh 0 & Heredity \\
\hline GFD-CD & $M / 3$ & NA & Marsh 1 & - \\
\hline GFD-CD & $F / 13$ & NA & Marsh 1 & - \\
\hline GFD-CD & $\mathrm{F} / 5$ & $\operatorname{Neg}(<4)$ & Marsh 1 & - \\
\hline GFD-CD & $M / 6$ & $\operatorname{Neg}(<4)$ & Marsh 1 & Heredity \\
\hline
\end{tabular}

$\mathrm{CD}=$ celiac disease, $\mathrm{GFD}=$ gluten-free diet, $\mathrm{TGA}=$ transglutaminase antibodies, $\mathrm{NA}=$ not analysed, Pot-CD=Potential CD. 


\section{Figure Legends}
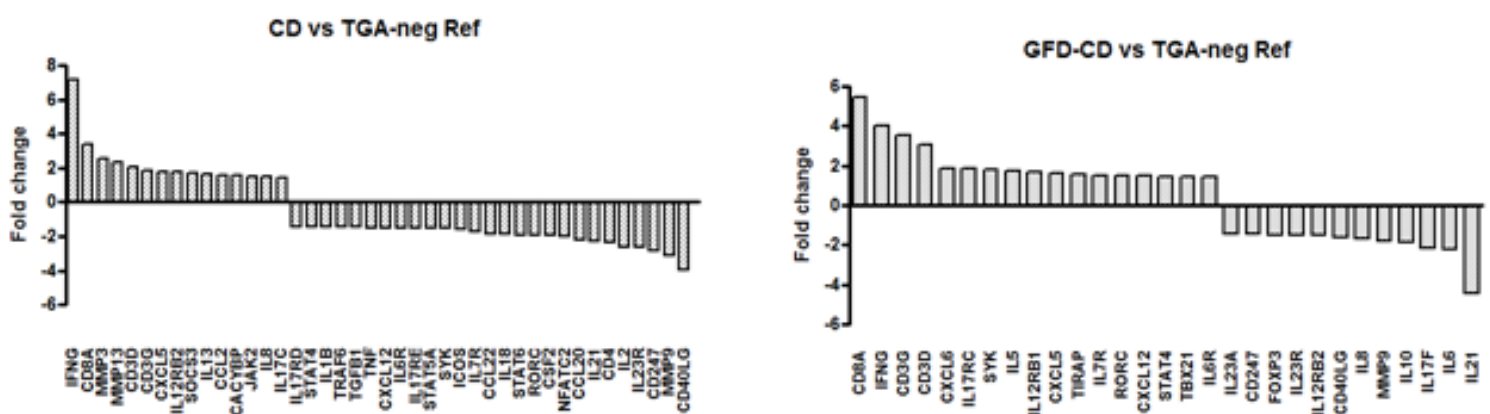

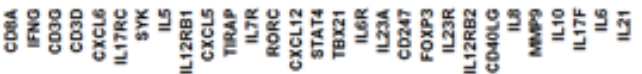
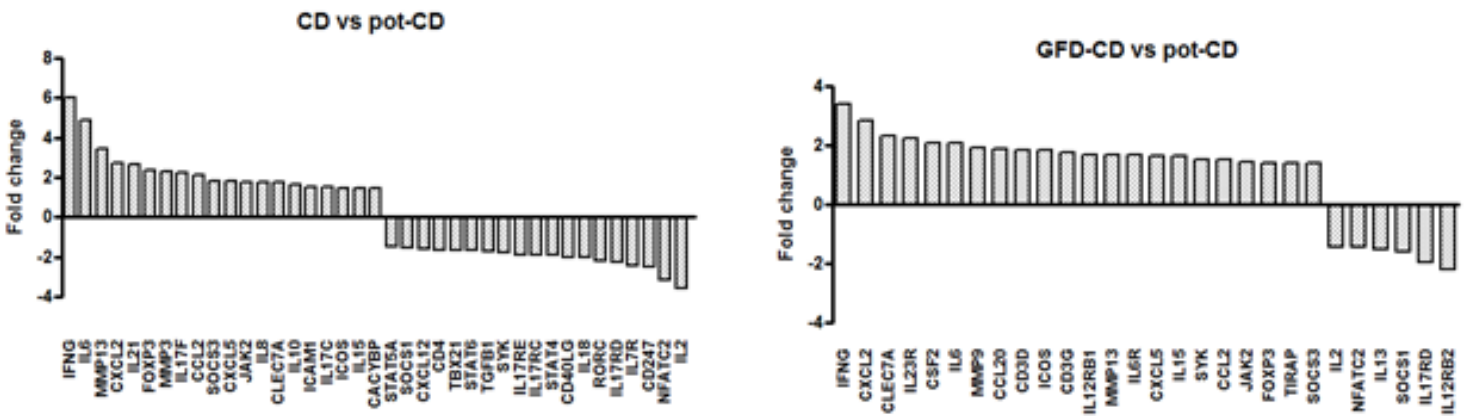

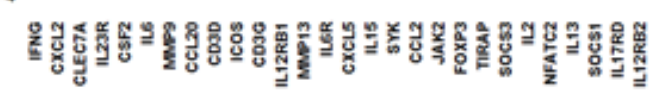
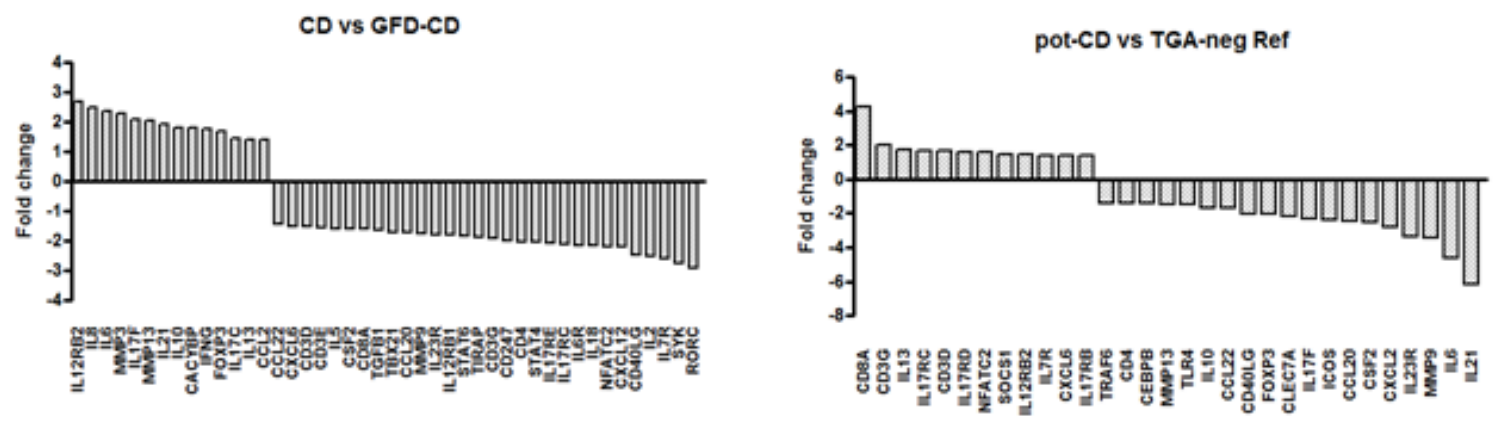

Figure 1. Fold change values $\left(2^{-\Delta \Delta C t}\right)$ of Th17 associated gene expression levels in biopsies from children with potential CD (pot-CD), untreated CD (CD) and GFD-treated CD (GFD-CD) and references (TGA-neg Ref). Cut off: $-1.4>$ x > 1.4. 


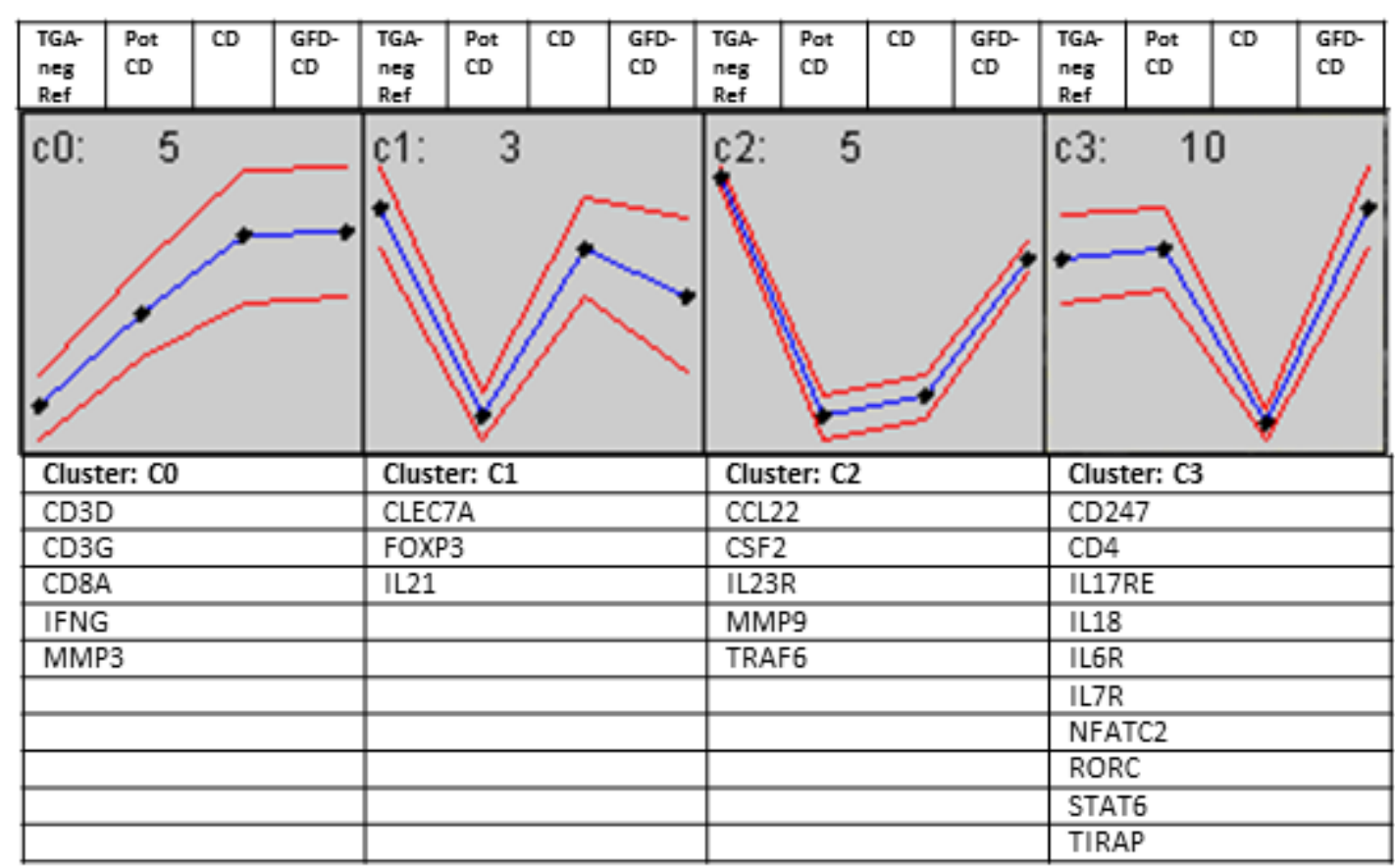

Figure 2. Gene expression profiles in biopsies from the study groups; TGA negative references, potential CD, untreated CD and GFD-treated CD. The expression patterns of the 23 genes passing the double cut-off criteria (a fold change $>1.4$ together with $\mathrm{p}<0.05$ ) are visualized in a selforganizing map (SOM)-cluster. The y-axis represents a relative scale with normalized gene expression. Lines connecting the dots indicate the mean expression profiles of the genes and the two outer lines indicate the standard deviation. 
A

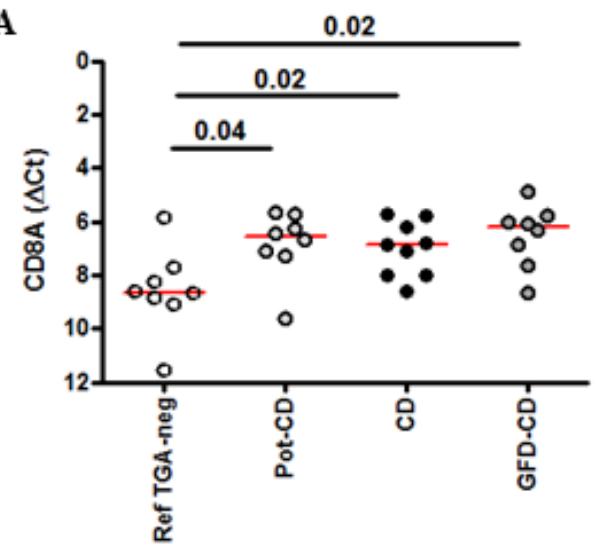

B
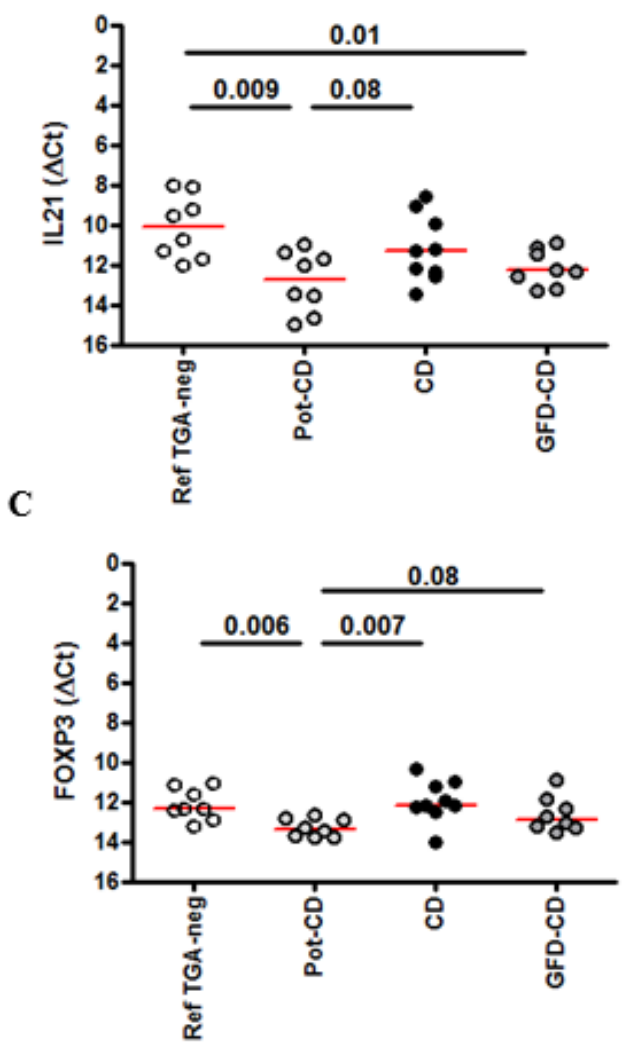

D

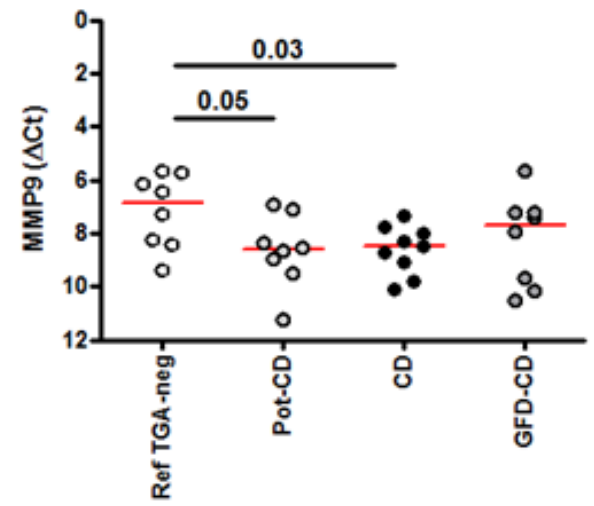

E

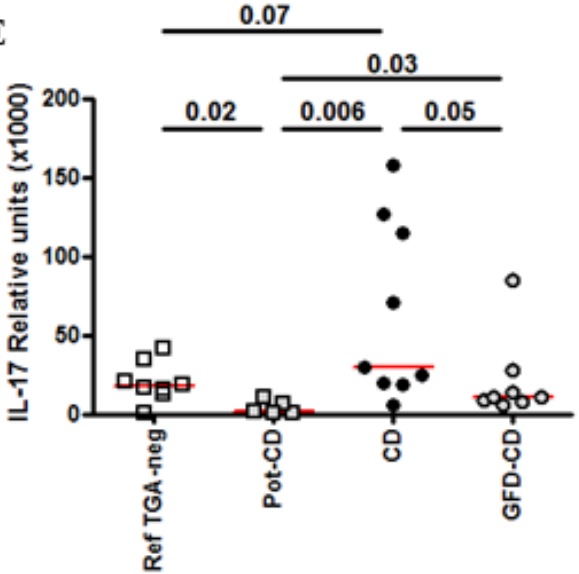

Figure 3. Th17 associated gene expression in small intestinal biopsies from children with potential $\mathrm{CD}$ (pot $\mathrm{CD}$ ), untreated $\mathrm{CD}(\mathrm{CD})$, gluten-free diet (GFD)-treated CD (GFD-CD) and references. The results from the real-time PCR analyses of CD8A (A), IL-21 (B), FOXP3 (C), MMP9 (D) are presented as $\Delta \mathrm{Ct}$-values, whereas the results from the qPCR analyses of IL-17A (E) is displayed as relative units. $\mathrm{P}$-values $<0.05$ were considered significant and $\mathrm{p}$-values $<0.10$ were considered as trends. 
A

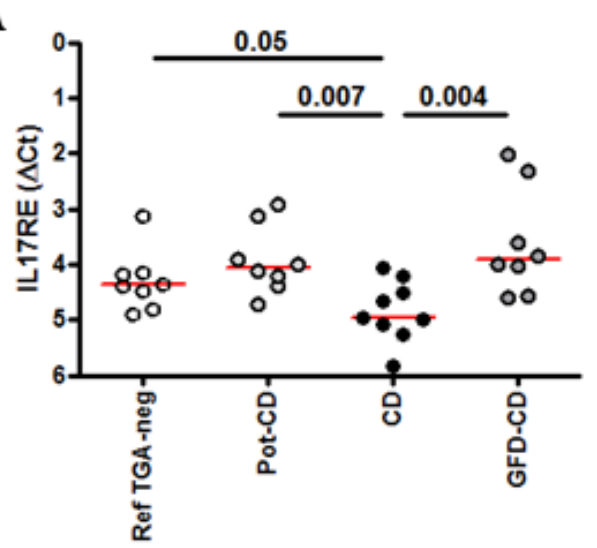

B

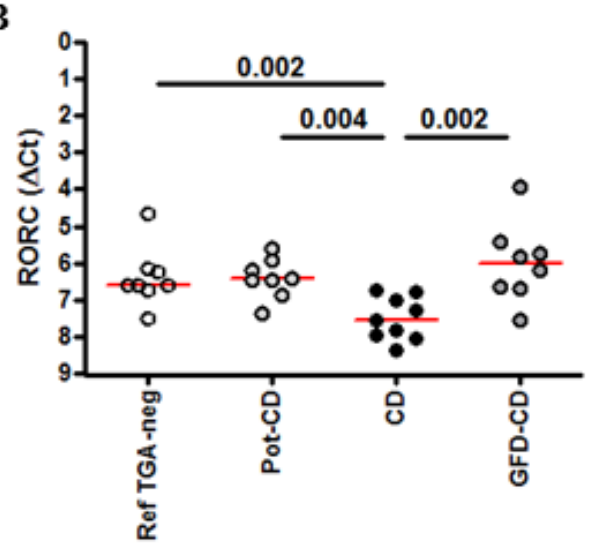

C

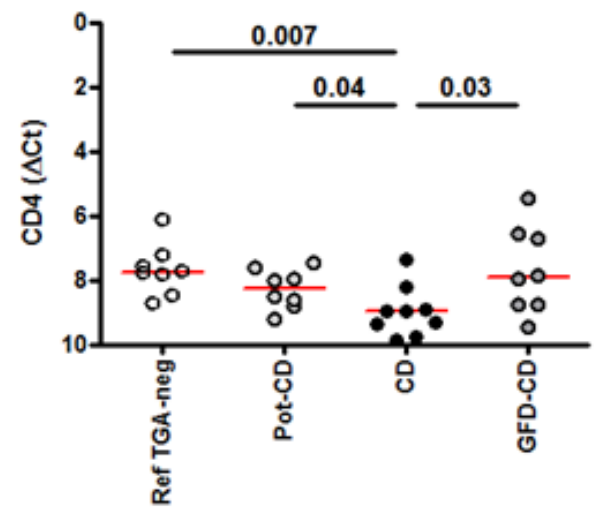

D

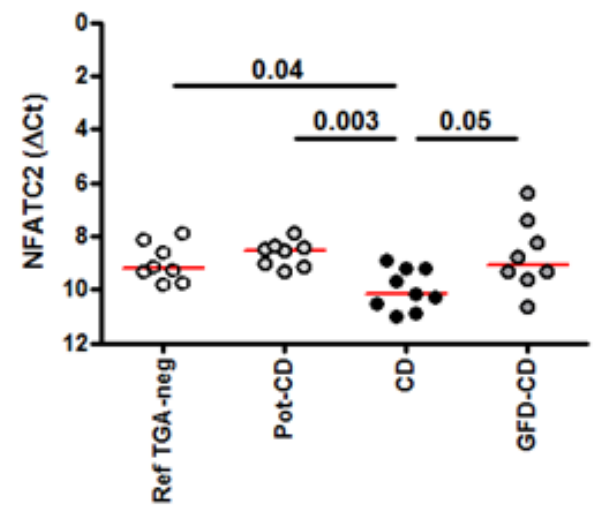

$\mathbf{E}$

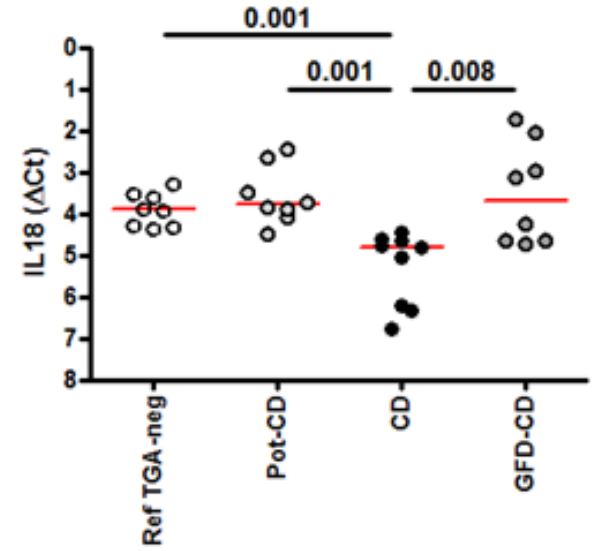

Figure 4. Th17 associated gene expression in small intestinal biopsies from children with potential CD (pot CD), untreated CD (CD), gluten-free diet (GFD)-treated CD (GFD-CD) and references. The results from the real-time PCR analyses of IL-17RE (A), RORc (B), CD4 (C), NFATC2 (D) and IL-18 (E) are presented as $\Delta$ Ct-values. P-values $<0.05$ were considered significant and p-values $<0.10$ were considered as trends. 
A

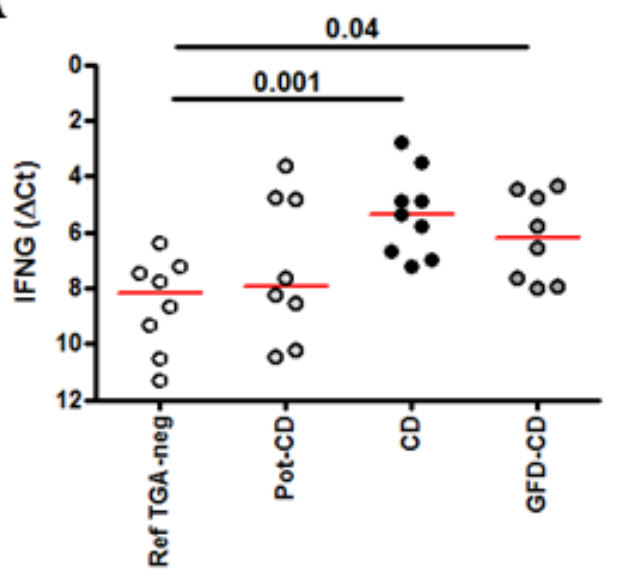

B

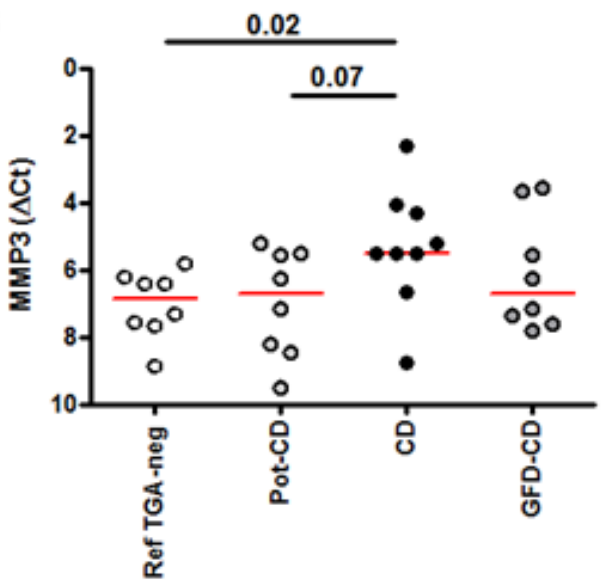

C

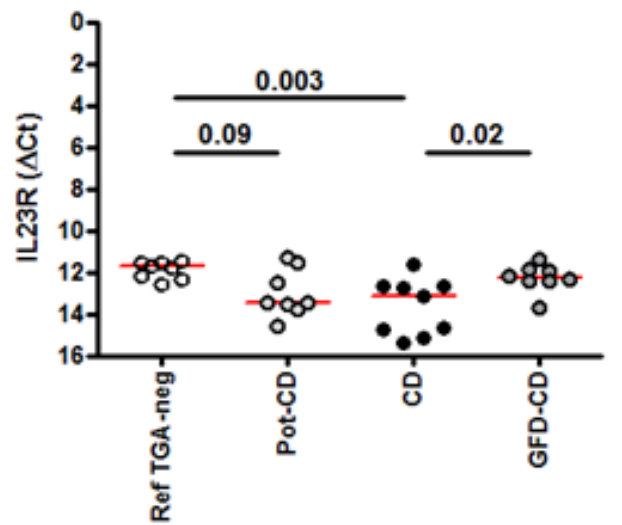

D

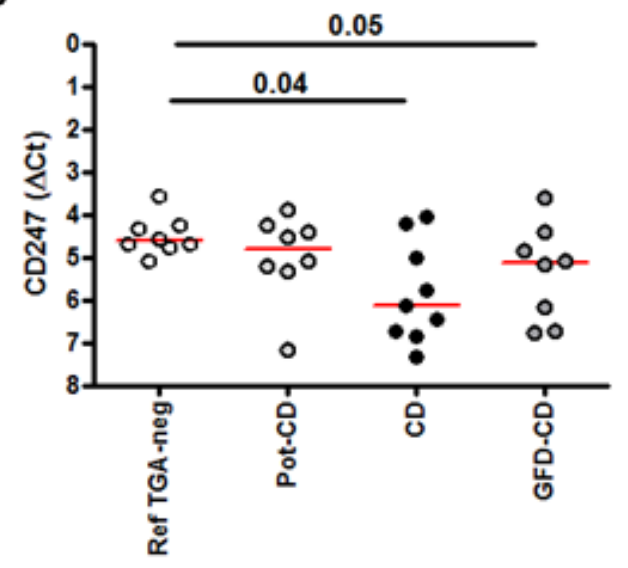

E

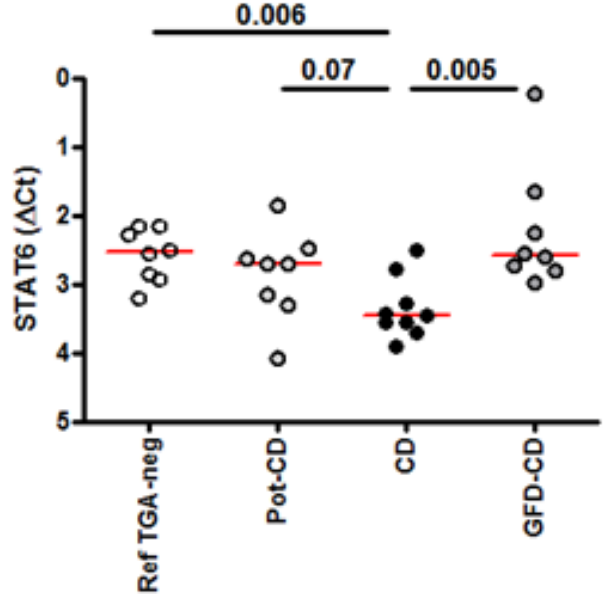

Figure 5. Th17 associated gene expression in small intestinal biopsies from children with potential CD (pot CD), untreated CD (CD), gluten-free diet (GFD)-treated CD (GFD-CD) and references.

The results from the real-time PCR analyses of IFN- $\gamma$ (A), MMP3 (B), IL-23R (C), CD247 (D) and STAT6 (E) are presented as $\Delta$ Ct-values. P-values $<0.05$ were considered significant and p-values $<0.10$ were considered as trends. 


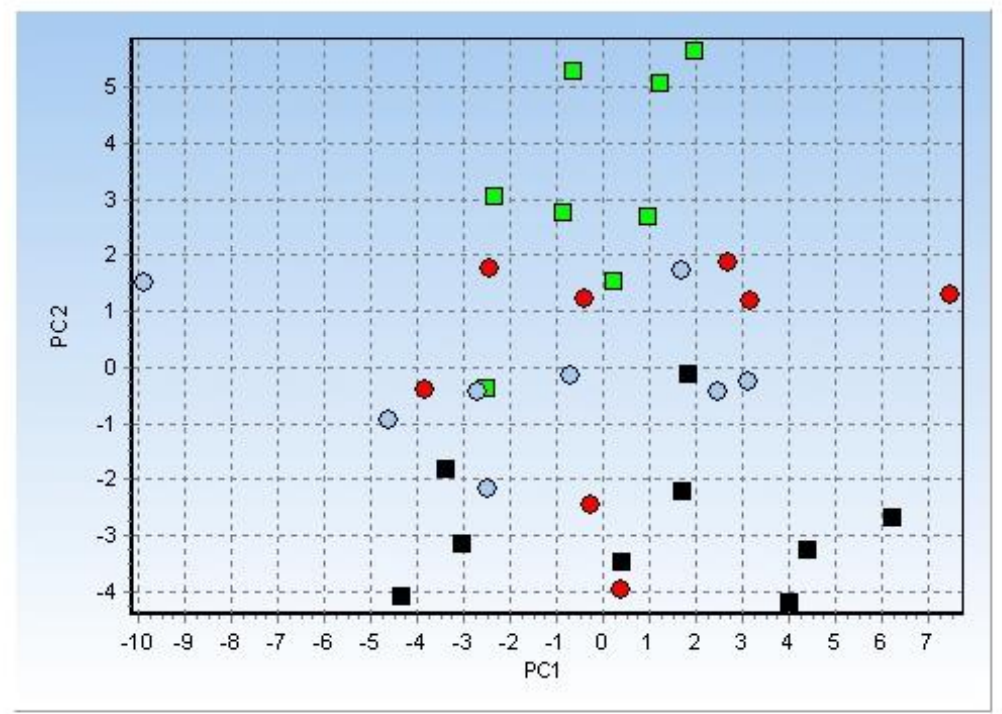
References
- Potential CD
Untreated CD
- GFD-treated CD

\begin{tabular}{|l|l|l|}
\hline \multicolumn{3}{|l|}{ Genes included in the PCA: } \\
\hline CCL22 & FOXP3 & MMP3 \\
\hline CD247 & IFN- $\gamma$ & MMP9 \\
\hline CD3D & IL-17RE & NFATC2 \\
\hline CD3G & IL-18 & RORC \\
\hline CD4 & IL-21 & STAT6 \\
\hline CD8A & IL-23R & TIRAP \\
\hline CLEC7A & IL-6R & TRAF6 \\
\hline CSF2 & IL-7R & \\
\hline
\end{tabular}

Figure 6. Principal component analysis (PCA) visualization (score plot) of gene expression data from intestinal biopsies, based on 23 of the genes (CCL22, CD247, CD3D, CD3G, CD4, CD8A, CLEC7A, CSF2, FOXP3, IFN- $\gamma$, IL-6R, IL-7R, IL-17RE, IL-18,IL-21, IL-23R, MMP3, MMP9, NFATC2, RORC, STAT6, TIRAP, TRAF6) displaying differential expression in untreated celiac disease (CD) (black), gluten-free diet (GFD)-treated CD (blue), children with potential CD (red) and reference children without $\mathrm{CD}$ (green). 


\section{Supplementary material}

Supplementary Table 1. The 84 genes studied in biopsies from the study subjects.

\begin{tabular}{|c|c|c|c|c|c|c|}
\hline & \multicolumn{2}{|c|}{ All individuals (groups) } & TGA- Ref & Pot CD & $C D$ & GFD-CD \\
\hline $\begin{array}{l}\text { Gene } \\
\text { abbreviation }\end{array}$ & $\begin{array}{l}\text { Response } \\
\text { ratio: } \\
\text { Pos/Total }\end{array}$ & $\begin{array}{l}\text { Analysed } \\
\text { statistically }\end{array}$ & $\begin{array}{l}\text { Response } \\
\text { ratio: } \\
\text { Pos/Total }\end{array}$ & $\begin{array}{l}\text { Response } \\
\text { ratio: } \\
\text { Pos/Total }\end{array}$ & $\begin{array}{l}\text { Response } \\
\text { ratio: } \\
\text { Pos/Total }\end{array}$ & $\begin{array}{l}\text { Response } \\
\text { ratio: } \\
\text { Pos/Total }\end{array}$ \\
\hline CACYBP & $32 / 33$ & Yes & $8 / 8$ & $8 / 8$ & 9/9 & $7 / 8$ \\
\hline CCL1 & $2 / 33$ & No & $1 / 8$ & $1 / 8$ & $0 / 9$ & $0 / 8$ \\
\hline CCL2 & $33 / 33$ & Yes & $8 / 8$ & $8 / 8$ & 9/9 & $8 / 8$ \\
\hline CCL20 & $33 / 33$ & Yes & $8 / 8$ & $8 / 8$ & $9 / 9$ & $8 / 8$ \\
\hline CCL22 & $33 / 33$ & Yes & $8 / 8$ & $8 / 8$ & 9/9 & $8 / 8$ \\
\hline CCL7 & $3 / 33$ & No & $1 / 8$ & $1 / 8$ & $1 / 9$ & $0 / 8$ \\
\hline CD247 & $33 / 33$ & Yes & $8 / 8$ & $8 / 8$ & 9/9 & $8 / 8$ \\
\hline CD28 & $10 / 33$ & No & $4 / 8$ & $3 / 8$ & $2 / 9$ & $1 / 8$ \\
\hline CD34 & $33 / 33$ & Yes & $8 / 8$ & $8 / 8$ & $9 / 9$ & $8 / 8$ \\
\hline CD3D & $33 / 33$ & Yes & $8 / 8$ & $8 / 8$ & 9/9 & $8 / 8$ \\
\hline CD3E & $33 / 33$ & Yes & $8 / 8$ & $8 / 8$ & 9/9 & $8 / 8$ \\
\hline CD3G & $33 / 33$ & Yes & $8 / 8$ & $8 / 8$ & 9/9 & $8 / 8$ \\
\hline CD4 & $33 / 33$ & Yes & $8 / 8$ & $8 / 8$ & 9/9 & $8 / 8$ \\
\hline CD4OLG & $33 / 33$ & Yes & $8 / 8$ & $8 / 8$ & 9/9 & $8 / 8$ \\
\hline CD8A & $33 / 33$ & Yes & $8 / 8$ & $8 / 8$ & $9 / 9$ & $8 / 8$ \\
\hline CEBPB & $33 / 33$ & Yes & $8 / 8$ & $8 / 8$ & $9 / 9$ & $8 / 8$ \\
\hline CLEC7A & $33 / 33$ & Yes & $8 / 8$ & $8 / 8$ & 9/9 & $8 / 8$ \\
\hline CSF2 & $29 / 33$ & Yes & $8 / 8$ & $5 / 8$ & $8 / 9$ & $8 / 8$ \\
\hline CSF3 & $7 / 33$ & No & $2 / 8$ & $2 / 8$ & $3 / 9$ & $0 / 8$ \\
\hline CX3CL1 & $32 / 33$ & Yes & $8 / 8$ & $7 / 8$ & $9 / 9$ & $8 / 8$ \\
\hline CXCL1 & $33 / 33$ & Yes & $8 / 8$ & $8 / 8$ & $9 / 9$ & $8 / 8$ \\
\hline CXCL12 & $33 / 33$ & Yes & $8 / 8$ & $8 / 8$ & $9 / 9$ & $8 / 8$ \\
\hline CXCL2 & $32 / 33$ & Yes & $8 / 8$ & $8 / 8$ & $9 / 9$ & $7 / 8$ \\
\hline CXCL5 & $21 / 33$ & Yes & $5 / 8$ & $5 / 8$ & $6 / 9$ & $5 / 8$ \\
\hline CXCL6 & $33 / 33$ & Yes & $8 / 8$ & $8 / 8$ & $9 / 9$ & $8 / 8$ \\
\hline EDG1 & $33 / 33$ & Yes & $8 / 8$ & $8 / 8$ & $9 / 9$ & $8 / 8$ \\
\hline FOXP3 & $31 / 33$ & Yes & $8 / 8$ & $7 / 8$ & $9 / 9$ & $7 / 8$ \\
\hline GATA3 & $32 / 33$ & Yes & $8 / 8$ & $8 / 8$ & $9 / 9$ & $7 / 8$ \\
\hline ICAM 1 & $33 / 33$ & Yes & $8 / 8$ & $8 / 8$ & $9 / 9$ & $8 / 8$ \\
\hline ICOS & $32 / 33$ & Yes & $8 / 8$ & $8 / 8$ & $9 / 9$ & $7 / 8$ \\
\hline IFNG & $33 / 33$ & Yes & $8 / 8$ & $8 / 8$ & $9 / 9$ & $8 / 8$ \\
\hline IL10 & $33 / 33$ & Yes & $8 / 8$ & $8 / 8$ & $9 / 9$ & $8 / 8$ \\
\hline IL12B & $13 / 33$ & No & $2 / 8$ & $2 / 8$ & $3 / 9$ & $6 / 8$ \\
\hline
\end{tabular}




\begin{tabular}{|c|c|c|c|c|c|c|}
\hline IL12RB1 & $33 / 33$ & Yes & $8 / 8$ & $8 / 8$ & $9 / 9$ & $8 / 8$ \\
\hline IL12RB2 & $33 / 33$ & Yes & $8 / 8$ & $8 / 8$ & $9 / 9$ & $8 / 8$ \\
\hline IL13 & 19/33 & Yes & $4 / 8$ & $5 / 8$ & $5 / 9$ & $5 / 8$ \\
\hline IL15 & $33 / 33$ & Yes & $8 / 8$ & $8 / 8$ & $9 / 9$ & $8 / 8$ \\
\hline IL17A & $0 / 33$ & No & $0 / 8$ & $0 / 8$ & $0 / 9$ & $0 / 8$ \\
\hline IL17C & $32 / 33$ & Yes & $8 / 8$ & $8 / 8$ & $9 / 9$ & $7 / 8$ \\
\hline IL17D & $13 / 33$ & No & $4 / 8$ & $1 / 8$ & $1 / 9$ & $7 / 8$ \\
\hline IL17F & $27 / 33$ & Yes & $8 / 8$ & $5 / 8$ & $9 / 9$ & $5 / 8$ \\
\hline IL17RB & $33 / 33$ & Yes & $8 / 8$ & $8 / 8$ & $9 / 9$ & $8 / 8$ \\
\hline IL17RC & $33 / 33$ & Yes & $8 / 8$ & $8 / 8$ & $9 / 9$ & $8 / 8$ \\
\hline IL17RD & $31 / 33$ & Yes & $8 / 8$ & $7 / 8$ & $9 / 9$ & $7 / 8$ \\
\hline IL17RE & $33 / 33$ & Yes & $8 / 8$ & $8 / 8$ & $9 / 9$ & $8 / 8$ \\
\hline IL18 & $33 / 33$ & Yes & $8 / 8$ & $8 / 8$ & $9 / 9$ & $8 / 8$ \\
\hline IL1B & $33 / 33$ & Yes & $8 / 8$ & $8 / 8$ & $9 / 9$ & $8 / 8$ \\
\hline IL2 & $31 / 33$ & Yes & $8 / 8$ & $7 / 8$ & $8 / 9$ & $8 / 8$ \\
\hline IL21 & $32 / 33$ & Yes & $8 / 8$ & $7 / 8$ & $9 / 9$ & $8 / 8$ \\
\hline IL22 & $13 / 33$ & No & $4 / 8$ & $2 / 8$ & $1 / 9$ & $5 / 8$ \\
\hline IL23A & $33 / 33$ & Yes & $8 / 8$ & $8 / 8$ & $9 / 9$ & $8 / 8$ \\
\hline IL23R & $26 / 33$ & Yes & $8 / 8$ & $6 / 8$ & $5 / 9$ & $7 / 8$ \\
\hline IL25 & $0 / 33$ & No & $0 / 8$ & $0 / 8$ & $0 / 9$ & $0 / 8$ \\
\hline IL27 & $0 / 33$ & No & $0 / 8$ & $0 / 8$ & $0 / 9$ & $0 / 8$ \\
\hline IL3 & $0 / 33$ & No & $0 / 8$ & $0 / 8$ & $0 / 9$ & $0 / 8$ \\
\hline IL4 & $6 / 33$ & No & $2 / 8$ & $0 / 8$ & $2 / 9$ & $2 / 8$ \\
\hline IL5 & $33 / 33$ & Yes & $8 / 8$ & $8 / 8$ & $9 / 9$ & $8 / 8$ \\
\hline IL6 & $25 / 33$ & Yes & $7 / 8$ & $4 / 8$ & $9 / 9$ & $5 / 8$ \\
\hline IL6R & $33 / 33$ & Yes & $8 / 8$ & $8 / 8$ & $9 / 9$ & $8 / 8$ \\
\hline IL7R & $33 / 33$ & Yes & $8 / 8$ & $8 / 8$ & $9 / 9$ & $8 / 8$ \\
\hline IL8 & $33 / 33$ & Yes & $8 / 8$ & $8 / 8$ & $9 / 9$ & $8 / 8$ \\
\hline ISG20 & $33 / 33$ & Yes & $8 / 8$ & $8 / 8$ & $9 / 9$ & $8 / 8$ \\
\hline JAK1 & $33 / 33$ & Yes & $8 / 8$ & $8 / 8$ & $9 / 9$ & $8 / 8$ \\
\hline JAK2 & $33 / 33$ & Yes & $8 / 8$ & $8 / 8$ & $9 / 9$ & $8 / 8$ \\
\hline MMP13 & $33 / 33$ & Yes & $8 / 8$ & $8 / 8$ & $9 / 9$ & $8 / 8$ \\
\hline MMP3 & $33 / 33$ & Yes & $8 / 8$ & $8 / 8$ & $9 / 9$ & $8 / 8$ \\
\hline MMP9 & $33 / 33$ & Yes & $8 / 8$ & $8 / 8$ & $9 / 9$ & $8 / 8$ \\
\hline NFATC2 & $33 / 33$ & Yes & $8 / 8$ & $8 / 8$ & $9 / 9$ & $8 / 8$ \\
\hline NFKB1 & $33 / 33$ & Yes & $8 / 8$ & $8 / 8$ & $9 / 9$ & $8 / 8$ \\
\hline RORC & $33 / 33$ & Yes & $8 / 8$ & $8 / 8$ & $9 / 9$ & $8 / 8$ \\
\hline socs1 & $33 / 33$ & Yes & $8 / 8$ & $8 / 8$ & $9 / 9$ & $8 / 8$ \\
\hline socs3 & $33 / 33$ & Yes & $8 / 8$ & $8 / 8$ & $9 / 9$ & $8 / 8$ \\
\hline
\end{tabular}




\begin{tabular}{|c|l|l|l|l|l|l|}
\hline STAT3 & $33 / 33$ & Yes & $8 / 8$ & $8 / 8$ & $9 / 9$ & $8 / 8$ \\
\hline STAT4 & $33 / 33$ & Yes & $8 / 8$ & $8 / 8$ & $9 / 9$ & $8 / 8$ \\
\hline STAT5A & $33 / 33$ & Yes & $8 / 8$ & $8 / 8$ & $9 / 9$ & $8 / 8$ \\
\hline STAT6 & $33 / 33$ & Yes & $8 / 8$ & $8 / 8$ & $9 / 9$ & $8 / 8$ \\
\hline SYK & $33 / 33$ & Yes & $8 / 8$ & $8 / 8$ & $9 / 9$ & $8 / 8$ \\
\hline TBX21 & $33 / 33$ & Yes & $8 / 8$ & $8 / 8$ & $9 / 9$ & $8 / 8$ \\
\hline TGFB1 & $33 / 33$ & Yes & $8 / 8$ & $8 / 8$ & $9 / 9$ & $8 / 8$ \\
\hline TIRAP & $33 / 33$ & Yes & $8 / 8$ & $8 / 8$ & $9 / 9$ & $8 / 8$ \\
\hline TLR4 & $33 / 33$ & Yes & $8 / 8$ & $8 / 8$ & $9 / 9$ & $8 / 8$ \\
\hline TNF & $33 / 33$ & Yes & $8 / 8$ & $8 / 8$ & $9 / 9$ & $8 / 8$ \\
\hline TRAF6 & $33 / 33$ & Yes & $8 / 8$ & $8 / 8$ & $9 / 9$ & $8 / 8$ \\
\hline YY1 & $33 / 33$ & Yes & $8 / 8$ & $8 / 8$ & $9 / 9$ & $8 / 8$ \\
\hline
\end{tabular}


Supplementary Table 2. Th17 associated gene expression levels in small intestinal biopsies from children with potential celiac disease (CD) (pot-CD), untreated CD (CD), gluten-free diet (GFD) treated CD (GFD-CD) and references (Ref). Mann-Whitney U test (M-W) was used for comparison of the gene expression levels ( $\Delta \mathrm{Ct}$ values) between the groups, $\mathrm{p}$-values $<0.05$ were considered significant and p-values $<0.10$ were considered as trends. Genes marked in bold displays differentially expressed genes between the groups; statistically (based on $\Delta$ Ct-values) and with fold change values $\left(2^{\wedge}\right.$-median $\left.\Delta \Delta \mathrm{Ct}\right)$ passing the cut off levels at: $-1.4 \geq \mathrm{x} \geq 1.4$.

\begin{tabular}{|c|c|c|c|c|c|c|c|c|c|c|}
\hline & $\begin{array}{c}\text { Ref } \\
\text { (TGA-) }\end{array}$ & Pot-CD & $C D$ & $\begin{array}{c}\text { GFD- } \\
C D\end{array}$ & $\begin{array}{c}\text { Pot-CD } \\
\text { vs } \\
\text { Ref } \\
\text { (TGA-) }\end{array}$ & $\begin{array}{c}C D \\
\text { vs } \\
\text { Ref } \\
(T G A-)\end{array}$ & $\begin{array}{c}\text { GFD- } \\
\text { CD } \\
\text { vs } \\
\text { Ref } \\
\text { (TGA-) }\end{array}$ & $\begin{array}{c}C D \\
\text { vs } \\
\text { Pot-CD }\end{array}$ & $\begin{array}{c}\text { GFD- } \\
C D \\
\text { vs } \\
\text { Pot-CD }\end{array}$ & $\begin{array}{c}\text { GFD- } \\
C D \\
\text { VS } \\
C D\end{array}$ \\
\hline $\begin{array}{l}\text { Gene } \\
\text { symbol }\end{array}$ & $\begin{array}{c}\text { Median } \\
\Delta \mathrm{Ct}\end{array}$ & $\begin{array}{c}\text { Median } \\
\Delta \mathrm{Ct}\end{array}$ & $\begin{array}{c}\text { Median } \\
\Delta \mathrm{Ct}\end{array}$ & $\begin{array}{c}\text { Median } \\
\Delta \mathrm{Ct}\end{array}$ & $M-W$ & $M-W$ & M-W & $M-W$ & $M-W$ & M-W \\
\hline CACYBP & 3.1 & 3.0 & 2.4 & 3.3 & n.s. & n.s. & n.s. & n.s. & n.s. & n.s. \\
\hline CCL2 & 5.3 & 5.8 & 4.6 & 5.1 & n.s. & n.s. & n.s. & n.s. & n.s. & n.s. \\
\hline CCL20 & 5.1 & 6.4 & 6.3 & 5.5 & 0.06 & n.s. & n.s. & n.s. & n.s. & n.s. \\
\hline CCL22 & 7.0 & 7.8 & 7.9 & 7.4 & n.s. & 0.02 & n.s. & n.s. & n.s. & n.s. \\
\hline CD247 & 4.6 & 4.8 & 6.1 & 5.1 & n.s. & 0.04 & 0.05 & n.s. & n.s. & n.s. \\
\hline CD34 & 6.1 & 6.0 & 6.1 & 6.2 & n.s. & n.s. & n.s. & n.s. & n.s. & n.s. \\
\hline CD3D & 3.5 & 2.8 & 2.5 & 1.9 & n.s. & 0.03 & 0.02 & n.s. & n.s. & n.s. \\
\hline CD3E & 5.0 & 4.8 & 5.2 & 4.6 & n.s. & n.s. & n.s. & n.s. & n.s. & n.s. \\
\hline CD3G & 5.4 & 4.4 & 4.5 & 3.6 & 0.07 & 0.01 & 0.05 & n.s. & n.s. & n.s. \\
\hline CD4 & 7.7 & 8.3 & 9.0 & 7.9 & n.s. & 0.007 & n.s. & 0.04 & n.s. & 0.03 \\
\hline CD40LG & 8.4 & 9.4 & 10.3 & 9.0 & n.s. & 0.06 & n.s. & n.s. & n.s. & n.s. \\
\hline CD8A & 8.6 & 6.6 & 6.9 & 6.2 & 0.04 & 0.02 & 0.02 & n.s. & n.s. & n.s. \\
\hline CEBPB & 6.3 & 6.8 & 6.3 & 6.4 & n.s. & n.s. & n.s. & n.s. & n.s. & n.s. \\
\hline CLEC7A & 9.5 & 10.6 & 9.8 & 9.3 & 0.05 & n.s. & n.s. & n.s. & 0.03 & 0.07 \\
\hline CSF2 & 11.7 & 13.1 & 12.7 & 12.0 & 0.05 & 0.10 & n.s. & n.s. & n.s. & n.s. \\
\hline CX3CL1 & 9.8 & 9.8 & 9.9 & 9.6 & n.s. & n.s. & n.s. & n.s. & n.s. & n.s. \\
\hline CXCL1 & 5.8 & 5.7 & 5.8 & 5.5 & n.s. & n.s. & n.s. & n.s. & n.s. & n.s. \\
\hline CXCL12 & 5.9 & 5.8 & 6.4 & 5.3 & n.s. & n.s. & n.s. & n.s. & n.s. & n.s. \\
\hline CXCL2 & 10.2 & 11.7 & 10.2 & 10.2 & n.s. & n.s. & n.s. & n.s. & n.s. & n.s. \\
\hline CXCL5 & 13.5 & 13.5 & 12.7 & 12.8 & n.s. & n.s. & n.s. & n.s. & n.s. & n.s. \\
\hline CXCL6 & 7.2 & 6.7 & 6.9 & 6.3 & n.s. & n.s. & n.s. & n.s. & n.s. & 0.10 \\
\hline EDG1 & 6.0 & 6.1 & 6.3 & 6.1 & n.s. & n.s. & n.s. & n.s. & n.s. & n.s. \\
\hline FOXP3 & 12.4 & 13.4 & 12.2 & 12.9 & 0.006 & n.s. & n.s. & 0.007 & 0.08 & n.s. \\
\hline GATA3 & 12.2 & 12.0 & 12.4 & 12.3 & n.s. & n.s. & n.s. & n.s. & n.s. & n.s. \\
\hline ICAM1 & 5.4 & 5.8 & 5.2 & 5.4 & n.s. & n.s. & n.s. & n.s. & n.s. & n.s. \\
\hline ICOS & 10.6 & 11.8 & 11.3 & 11.0 & n.s. & n.s. & n.s. & n.s. & n.s. & n.s. \\
\hline IFNG & 8.2 & 8.0 & 5.4 & 6.2 & n.s. & 0.001 & 0.04 & n.s. & n.s. & n.s. \\
\hline IL10 & 9.4 & 10.1 & 9.4 & 10.3 & n.s. & n.s. & n.s. & n.s. & n.s. & n.s. \\
\hline IL12RB1 & 7.6 & 7.6 & 7.7 & 6.9 & n.s. & n.s. & n.s. & n.s. & n.s. & n.s. \\
\hline IL12RB2 & 10.0 & 9.5 & 9.2 & 10.6 & n.s. & n.s. & n.s. & n.s. & n.s. & n.s. \\
\hline IL13 & 13.9 & 13.1 & 13.2 & 13.7 & n.s. & n.s. & n.s. & n.s. & n.s. & n.s. \\
\hline IL15 & 4.9 & 5.3 & 4.8 & 4.6 & n.s. & n.s. & n.s. & n.s. & n.s. & n.s. \\
\hline IL17C & 12.0 & 12.1 & 11.5 & 12.1 & n.s. & n.s. & n.s. & n.s. & n.s. & n.s. \\
\hline IL17F & 12.4 & 13.7 & 12.5 & 13.6 & 0.06 & n.s. & n.s. & n.s. & n.s. & n.s. \\
\hline IL17RB & 5.4 & 4.9 & 5.1 & 5.2 & n.s. & 0.10 & n.s. & n.s. & n.s. & n.s. \\
\hline IL17RC & 6.5 & 5.7 & 6.7 & 5.6 & n.s. & n.s. & n.s. & n.s. & n.s. & n.s. \\
\hline IL17RD & 10.8 & 10.1 & 11.3 & 11.1 & n.s. & n.s. & n.s. & n.s. & n.s. & n.s. \\
\hline IL17RE & 4.4 & 4.1 & 5.0 & 3.9 & 0.10 & 0.05 & 0.09 & 0.007 & n.s. & 0.004 \\
\hline IL18 & 3.9 & 3.8 & 4.8 & 3.7 & n.s. & 0.001 & n.s. & 0.001 & n.s. & 0.008 \\
\hline
\end{tabular}




\begin{tabular}{|c|c|c|c|c|c|c|c|c|c|c|}
\hline IL1B & 8.5 & 8.8 & 9.1 & 8.6 & n.s. & n.s. & n.s. & n.s. & n.s. & n.s. \\
\hline IL2 & 10.0 & 9.6 & 11.4 & 10.1 & n.s. & n.s. & n.s. & n.s. & n.s. & n.s. \\
\hline IL21 & 10.1 & 12.8 & 11.3 & 12.3 & 0.009 & n.s. & 0.01 & 0.08 & n.s. & n.s. \\
\hline IL23A & 9.1 & 9.4 & 9.2 & 9.6 & n.s. & n.s. & n.s. & n.s. & n.s. & n.s. \\
\hline IL23R & 11.7 & 13.5 & 13.1 & 12.3 & 0.09 & 0.003 & n.s. & n.s. & n.s. & 0.02 \\
\hline IL5 & 11.6 & 11.2 & 11.5 & 10.8 & n.s. & n.s. & 0.09 & n.s. & n.s. & n.s. \\
\hline IL6 & 11.5 & 13.7 & 11.4 & 12.6 & n.s. & n.s. & n.s. & n.s. & n.s. & n.s. \\
\hline IL6R & 5.6 & 5.8 & 6.2 & 5.1 & n.s. & n.s. & n.s. & n.s. & 0.09 & 0.03 \\
\hline IL7R & 8.8 & 8.3 & 9.6 & 8.2 & n.s. & n.s. & n.s. & n.s. & n.s. & 0.04 \\
\hline IL8 & 7.7 & 8.0 & 7.2 & 8.5 & n.s. & n.s. & n.s. & n.s. & n.s. & n.s. \\
\hline ISG20 & 2.2 & 2.2 & 2.3 & 2.1 & n.s. & n.s. & n.s. & n.s. & n.s. & n.s. \\
\hline JAK1 & 2.3 & 2.1 & 2.4 & 2.4 & n.s. & n.s. & n.s. & n.s. & n.s. & n.s. \\
\hline JAK2 & 5.5 & 5.8 & 4.9 & 5.2 & n.s. & n.s. & n.s. & n.s. & n.s. & n.s. \\
\hline MMP13 & 10.9 & 11.4 & 9.6 & 10.7 & n.s. & n.s. & n.s. & n.s. & n.s. & n.s. \\
\hline MMP3 & 6.9 & 6.7 & 5.5 & 6.7 & n.s. & 0.02 & n.s. & 0.07 & n.s. & n.s. \\
\hline MMP9 & 6.9 & 8.6 & 8.5 & 7.7 & 0.05 & 0.03 & n.s. & n.s. & n.s. & n.s. \\
\hline NFATC2 & 9.2 & 8.5 & 10.2 & 9.1 & n.s. & 0.04 & n.s. & 0.003 & n.s. & 0.05 \\
\hline NFKB1 & 3.3 & 3.1 & 3.0 & 3.3 & n.s. & n.s. & n.s. & n.s. & n.s. & n.s. \\
\hline RORC & 6.6 & 6.4 & 7.5 & 6.0 & n.s. & 0.002 & n.s. & 0.004 & n.s. & 0.002 \\
\hline SOCS1 & 6.9 & 6.4 & 7.0 & 7.1 & n.s. & n.s. & n.s. & n.s. & n.s. & n.s. \\
\hline SOCS3 & 7.2 & 7.3 & 6.4 & 6.8 & n.s. & n.s. & n.s. & n.s. & n.s. & n.s. \\
\hline STAT3 & 2.7 & 2.9 & 2.7 & 2.7 & n.s. & n.s. & n.s. & n.s. & n.s. & n.s. \\
\hline STAT4 & 6.4 & 6.0 & 6.9 & 5.9 & n.s. & n.s. & n.s. & n.s. & n.s. & n.s. \\
\hline STAT5A & 6.0 & 6.0 & 6.6 & 6.4 & n.s. & n.s. & n.s. & n.s. & n.s. & n.s. \\
\hline STAT6 & 2.5 & 2.7 & 3.5 & 2.6 & n.s. & 0.006 & n.s. & 0.07 & n.s. & 0.005 \\
\hline SYK & 6.8 & 6.6 & 7.4 & 6.0 & n.s. & n.s. & n.s. & n.s. & n.s. & n.s. \\
\hline TBX21 & 8.6 & 8.1 & 8.9 & 8.1 & n.s. & n.s. & n.s. & n.s. & n.s. & n.s. \\
\hline TGFB1 & 5.0 & 4.8 & 5.5 & 4.8 & n.s. & n.s. & n.s. & n.s. & n.s. & n.s. \\
\hline TIRAP & 8.4 & 8.2 & 8.7 & 7.8 & n.s. & n.s. & n.s. & 0.10 & n.s. & 0.02 \\
\hline TLR4 & 7.3 & 7.9 & 7.6 & 7.5 & n.s. & n.s. & n.s. & n.s. & n.s. & n.s. \\
\hline TNF & 6.7 & 7.2 & 7.3 & 7.0 & n.s. & n.s. & n.s. & n.s. & n.s. & n.s. \\
\hline TRAF6 & 5.3 & 5.8 & 5.9 & 5.5 & 0.002 & 0.001 & n.s. & n.s. & n.s. & 0.10 \\
\hline YY1 & 3.7 & 3.7 & 3.4 & 3.5 & n.s. & n.s. & n.s. & n.s. & n.s. & n.s. \\
\hline
\end{tabular}

